\title{
Clinical features of Crohn's disease in Korean patients residing in Busan and Gyeongnam
}

\author{
Eun Ji Lee ${ }^{1}$, Tae Oh Kim ${ }^{1}$, Geun Am Song ${ }^{2}$, Jong hun Lee ${ }^{3}$, Hyung Wook Kim², Sam Ryong Jee, \\ Seun Ja Park ${ }^{5}$, Hyun Jin Kim ${ }^{6}$, Jong Ha Park ${ }^{1}$ \\ ${ }^{1}$ Department of Internal Medicine, Haeundae Paik Hospital, Inje University College of Medicine, Busan, ${ }^{2}$ Division of Gastroenterology, \\ Department of Internal Medicine, Pusan National University School of Medicine, Busan, ${ }^{3}$ Division of Gastroenterology, Department of \\ Internal Medicine, Dong-A University Medical Center, Busan, ${ }^{4}$ Department of Internal Medicine, BusanPaik Hospital, Inje University College \\ of Medicine, Busan, ${ }^{5}$ Division of Gastroenterology, Department of Internal Medicine, Kosin University College of Medicine, Busan, ${ }^{6}$ Division of \\ Gastroenterology, Department of Internal Medicine, Gyeongsang National University School of Medicine, Jinju, Korea
}

Background/Aims: Crohn's disease (CD) is a chronic inflammatory bowel disease that presents with variable features and repeated disease aggravation. The incidence of CD is increasing in Korea. We evaluated the clinical features of CD in a study population in Busan and Gyeongnam, Korea. Methods: A hospital-based analysis included 619 patients diagnosed with CD between March 1986 and February 2013 from seven tertiary care hospitals in Busan and Gyeongnam. Individual case records were reviewed with regard to age at diagnosis, sex, disease location, disease behavior, and medical and surgical treatments received during the follow-up period. Results: The cumulative frequency of patients diagnosed with CD revealed a continued increase in the number of cases reported yearly. The male-to-female ratio was 2.5:1 and the median age at diagnosis was 24 years. At diagnosis, 114 (18.4\%) had isolated small bowel disease, 144 (23.3\%) had isolated colonic disease, and 358 patients (57.8\%) presented with disease in the small bowel and colon. The number of patients presenting with stricturing or penetrating disease behavior was 291 (47\%) at the final evaluation. In total, 111 (17.9\%) patients underwent intestinal resections. Conclusions: A continued increase in the number of patients diagnosed with CD was found in Busan and Gyeongnam as observed in other regions. We report results similar to that of other Korean studies in terms of sex distribution, age, and location of disease. (Intest Res 2016;14:30-36)

Key Words: Crohn disease; Inflammatory bowel diseases; Clinical features; Intestinal resection

\section{INTRODUCTION}

Crohn's disease (CD) is a chronic, lifelong disease with uncertain etiology and a pathophysiology that can affect any gastrointestinal site from the mouth to the anal canal. Disease onset usually occurs during adolescence and patients often experience severe disease flares and complications,

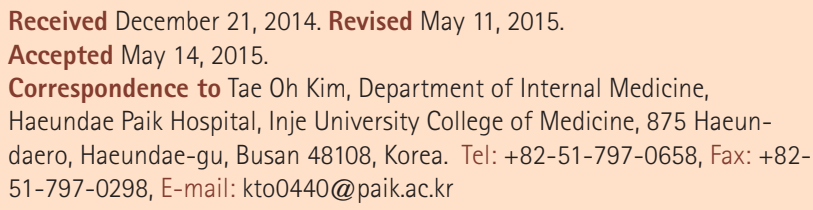

Financial support: None. Conflict of interest: None. leading to hospitalization and surgery.

The incidence and prevalence of CD have been increasing worldwide. Data suggest that the incidence rate of $\mathrm{CD}$ varies between 0.1 and 20/100,000 persons worldwide. ${ }^{1-4}$ The prevalence of CD ranges from 10 to 505 per 100,000 people, and North American studies have shown a prevalence as high as 200 per 100,000 people. ${ }^{5-7}$ The incidence and prevalence rates of $\mathrm{CD}$ have continued to rise in other areas, such as Asia and the developing world, that previously had much lower rates. ${ }^{8.9}$ Many epidemiological studies have shown that the incidence of CD is increasing in Korea. Most previous studies based on data collected from medical facilities in Seoul have examined clinical features such as sex distribution, disease location, and disease behavior in Korean CD

\footnotetext{
๑ Copyright 2016. Korean Association for the Study of Intestinal Diseases. All rights reserved.

This is an Open Access article distributed under the terms of the Creative Commons Attribution Non-Commercial License (http://creativecommons.org/licenses/by-nc/4.0)

which permits unrestricted non-commercial use, distribution, and reproduction in any medium, provided the original work is properly cited.
} 
patients compared to Caucasian patients. ${ }^{9-15}$ The aim of this study was to assess the epidemiological and clinical features of CD in a study population in Busan and Gyeongnam and to compare the results with those of studies conducted at other Korean medical facilities and world institutions.

\section{METHODS}

\section{Study Population}

This was a hospital-based study of all cases of CD diagnosed from 1986 to 2013 and followed in seven tertiary care hospitals (Gyeongsang National University Hospital, Kosin University Gospel Hospital, Dong-A University Hospital, Pusan National University Hospital, Inje University Busan Paik Hospital, Pusan National University Yangsan Hospital, and Inje University Haeundae Paik Hospital) in Busan and Gyeongnam, Korea. In total, 619 patients were diagnosed with definite $\mathrm{CD}$ in these hospitals. This study was approved by the institutional review board.

\section{Methods}

This was a retrospective, observational study based on the medical records of patients in multiple centers. Patients were diagnosed with CD if they met at least two of the following criteria: (1) a history of abdominal pain, weight loss, malaise, diarrhea, and/or rectal bleeding, (2) endoscopic findings of mucosal cobble-stoning, linear ulceration, skip areas, or perianal disease, (3) radiologic findings of stricture, fistula, mucosal cobble-stoning, or ulceration, (4) macroscopic appearance of bowel wall induration, mesenteric lymphadenopathy, and "creeping fat" on laparotomy, and (5) pathology findings of transmural inflammation and/or epithelioid granulomas. ${ }^{16}$ We reviewed the age at diagnosis, sex of patients, and the location and behavior of the disease. Other medical records including patient medical history, the presence of perianal fistula, previous anti-tuberculosis (TB) medication use, use of immunosuppressants (Azathioprine/6-mercaptopurine $[\mathrm{AZA} / 6-\mathrm{MP}]$ ) and biologic agents (anti-tumor necrosis factor $[\mathrm{TNF}]-\alpha$ inhibitor), and intestinal resection were obtained. Patients were sub-grouped based on the location and presentation of disease following the Montreal classification criteria. ${ }^{17}$ The location criteria (L1, small bowel; L2, colon; L3, small bowel and colon; L4, isolated upper disease) and behavioral attributes (B1, inflammatory; B2, structuring; B3, penetrating) of the disease were noted for each patient. ${ }^{18}$ Based on the predominant clinical, radiological, endoscopic, and surgical features, each patient was classified into one of the three patterns.

\section{Statistics}

All statistical analyses were conducted using SPSS software (ver. 18.0; SPSS Inc., Chicago, IL, USA). Depending on the characteristics of the data, frequencies such as mean, median, and SD were calculated for numerical variables, and number and percentages were calculated for categorical variables. Fisher's exact test, $\chi^{2}$ analysis, and Student's $t$-test were used to calculate differences and correlation of variables. All the significant variables $(P$-values $<0.1)$ from univariate analysis (age, sex, disease location, disease behavior and perianal disease) were assessed for correlation to risk of intestinal resection by multiple logistic regression analysis. $P$-values $<0.05$ were considered to indicate statistical significance. The cumulative probability of intestinal resection was calculated using the Kaplan-Meier method.

\section{RESULTS}

\section{Demographic Characteristics}

The number of patients with CD included in the study was 619 . The number of newly detected cases of patients diagnosed with CD demonstrated a trend of a progressive increase (Fig. 1).

The median age at diagnosis was 24 (range, 5-75) years and the mean age $( \pm$ SD) was $27( \pm 11.99)$ years; $95(15.3 \%)$

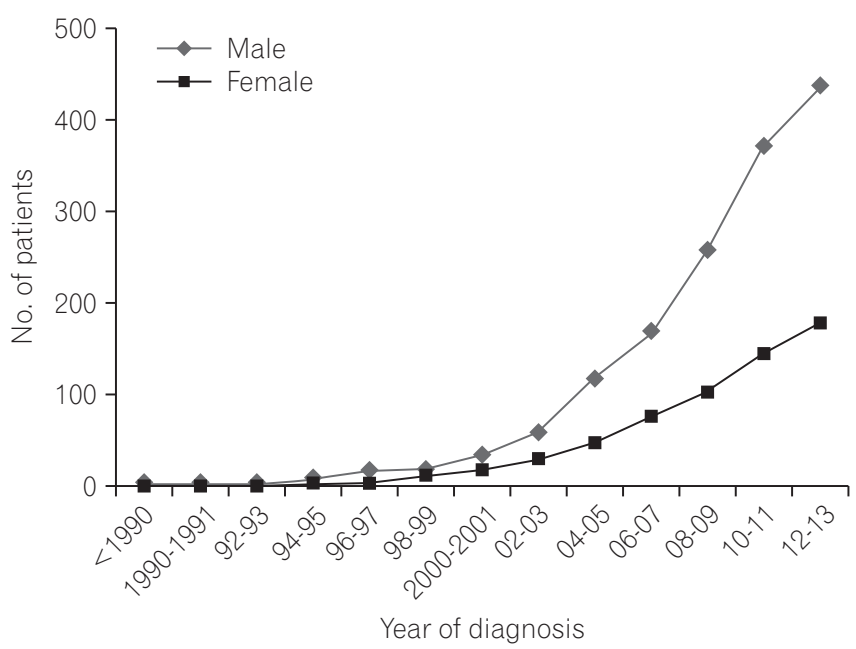

Fig. 1. Cumulative frequency. The number of cases of patients diagnosed with CD increased over time. 
patients were aged $<16$ years, $444(71.7 \%)$ were aged $17-40$ years, and $80(12.9 \%)$ were aged $>40$ years. The male-to-female ratio in the patient group was 2.5:1 (Fig. 2). The median duration of follow-up was $62 \pm 52.26$ (range, 1-324) months. The demographic characteristics of the patients at diagnosis are summarized in Table 1.

\section{Previous Administration of Anti-TB Medication}

In the study group, 45 patients (7.3\%) had received anti-TB medication, based on the clinical impression of intestinal TB (ITB) or for differentiating ITB from CD. Anti-TB therapy was not effective in any of the treated patients and all 45 patients were ultimately diagnosed with CD. We divided the patients who were diagnosed with $\mathrm{CD}$ during recent 12 years into two groups (2002-2007 and 2008-2013) , there were significant differences between the two groups in the frequency of patients misdiagnosed with ITB ( $12.7 \%$ and $5.9 \%, P=0.04)$.

\section{Location and Behavior of Disease}

The procedures used for the evaluation of disease location at diagnosis included colonoscopy in 607 patients (98.1\%), CT in 432 patients (69.8\%), small bowel series in 394 patients (63.7\%), esophagogastroduodenoscopy in 47 patients (7.6\%), double-contrast barium enema in 21 patients (3.4\%), bowel surgery in 14 patients $(2.3 \%)$, capsule endoscopy in 8 patients (1.3\%).

The isolated small bowel (L1) in 114 patients (18.4\%), isolated colon (L2) in 144 patients (23.3\%), and small bowel and colon (L3) in 358 patients (57.8\%) were observed to be the affected regions. Only 3 patients $(0.5 \%)$ presented with isolated upper disease and 11(1.8\%) presented with more

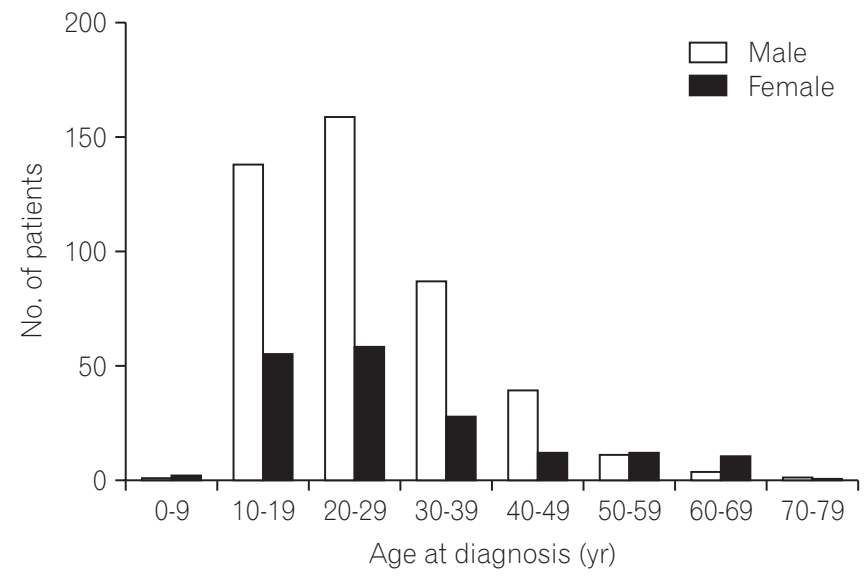

Fig. 2. Age and sex distribution at diagnosis of CD. The incidence of the 20-29-year-old age group for male and female was highest. distal disease concomitant with upper disease.

Patients presenting with ileo-colonic disease were significantly younger $(25.8 \pm 11.3$ years) than patients presenting with ileal or colonic disease $(28.2 \pm 11.5$ and $29.3 \pm 13.6$ years, respectively; $P=0.02$ ).

Disease presentation at diagnosis was inflammatory (B1) in 424 patients (68.5\%), stricturing (B2) in 89 (14.4\%), and penetrating (B3) in 106 (17.1\%). Of the patients initially presenting with B1 type disease, $96(22.6 \%)$ progressed to more aggravated disease behavior by their last evaluation; 45 (10.6\%) were B2, and 51 (12\%) were B3. In the patients who had disease behavior changes, 81 (84\%) patients had ileo-colonic disease, 72 (75\%) were male, and median age of

Table 1. Clinical Characteristics of Patients With CD at Diagnosis and Follow-up

\begin{tabular}{|c|c|}
\hline Characteristics at diagnosis & $n=619$ \\
\hline Male gender & $440(71.1)$ \\
\hline \multicolumn{2}{|l|}{$\mathrm{Age}^{\mathrm{a}}$} \\
\hline Median age at diagnosis (yr) & 24 \\
\hline $\mathrm{A} 1$ & $95(15.3)$ \\
\hline A2 & $444(71.7)$ \\
\hline A3 & 80 (12.9) \\
\hline \multicolumn{2}{|l|}{ Disease location at diagnosis $^{a}$} \\
\hline L1 & $114(18.4)$ \\
\hline L2 & $144(23.3)$ \\
\hline L3 & $358(57.8)$ \\
\hline Isolated L4 & $3(0.5)$ \\
\hline \multicolumn{2}{|l|}{ Disease behavior at diagnosis $^{\mathrm{a}}$} \\
\hline B1 & 424 (68.5) \\
\hline B2 & $89(14.4)$ \\
\hline B3 & $106(17.1)$ \\
\hline Perianal fistula & $132(21.3)$ \\
\hline Previous anti-tuberculous medication & $45(7.3)$ \\
\hline \multicolumn{2}{|l|}{ Follow-up results } \\
\hline Duration of follow-up (mo) & $62.0 \pm 52.3$ \\
\hline \multicolumn{2}{|l|}{ Medication and surgery } \\
\hline Intestinal resection & $111(17.9)$ \\
\hline AZA or 6-MP & $298(48.1)$ \\
\hline Anti-TNF- $\alpha$ agent & $98(15.8)$ \\
\hline
\end{tabular}

Values are presented as mean \pm SD or $n(\%)$.

${ }^{a}$ Age, disease location, and disease behavior in CD based on the Montreal classification.

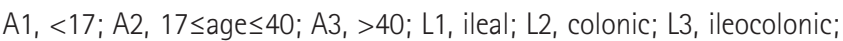
L4, upper gastrointestinal; B1, non-stricturing, non-penetrating; B2, stricturing; $B 3$, penetrating.

AZA, azathioprine; 6-MP, 6-mercaptopurine; TNF, tumor necrosis factor. 
patients was 23 (range, 13-66) years. However, after adjusting for other variables, there was no statistically significant difference between patients who showed behavioral change and who did not.

There were 132 (21.3\%) patients who presented with active perianal fistulas or reported a history of perianal fistulas. The patients presenting with perianal fistulas exhibited a higher proportion of penetrating disease (8.8\% vs. $47.7 \%$, $P<0.01$ ), ileo-colonic disease ( $55.4 \%$ vs. $65.2 \%, P=0.02$ ). Of the patients aged $\leq 16$ years (A1), 29 (31.3\%) presented with perianal fistulas (A2: $20.1 \%, \mathrm{~A} 3: 9.3 \%, P<0.01)$.

\section{Intestinal Resection}

In total, 111 patients (17.9\%) underwent intestinal resection, with a cumulative probability of intestinal resection 1 , 5,10 , and 20 years after diagnosis corresponding to $10.3 \%$, $14.0 \%, 16.7 \%$, and $36.9 \%$, respectively (Fig. 3). Male sex, older patients, and patients presenting with ileal disease seemed to have an association with intestinal resection but multiple logistic regression analysis revealed that only two significant factors associated with a higher incidence of surgery: disease behavior at diagnosis $(P<0.01)$ and, absence of perianal fistula $(P<0.01)$ (Table 2). Overall intestinal resection rate was $17.9 \%$, while $52(54.2 \%)$ out of 96 patients who had progressed to more aggravated disease behaviors underwent intestinal resection.

The intestinal resection rate of AZA/6-MP users was $16.4 \%$ (49/298), which was not significantly different from that of AZA/6-MP non-users (15.3\% [49/321], $P=0.079)$. Regarding anti-TNF- $\alpha$ agents, there were no differences in intestinal resection rate between users and non -users $(22.4 \%$ [22/98] vs.

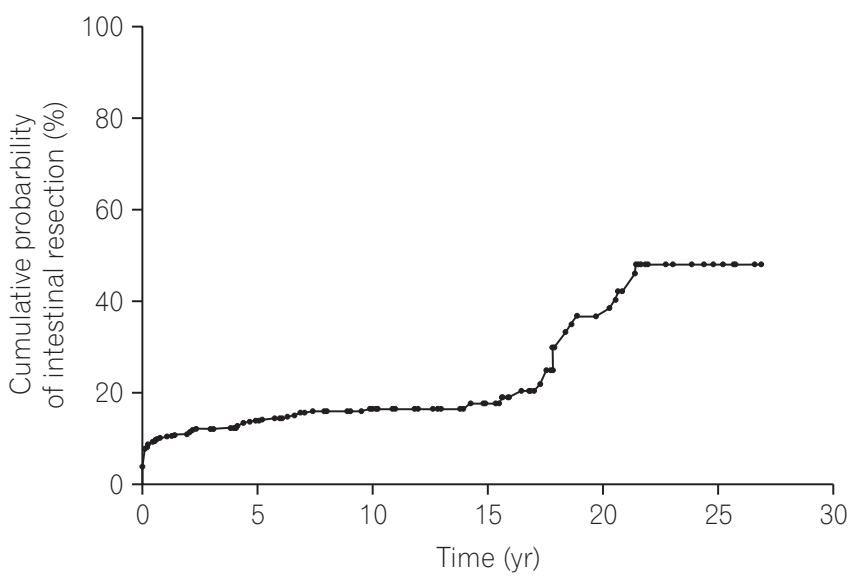

Fig. 3. Cumulative probability of intestinal resection during follow-up. It was $10.3 \%, 14.0 \%, 16.7 \%$, and $36.9 \%$ at 1, 5, 10 and 20 years.
$14.6 \%[76 / 521], P=0.359)$.

\section{DISCUSSION}

This large, multi-center study of 619 CD cases from Busan and Gyeongnam in Korea assessed the age at diagnosis, sex, disease location, disease behavior presence of perianal fistulas, use of AZA/6-MP and anti-TNF- $\alpha$ agents, and the characteristics of patients who underwent intestinal resections. The median age at diagnosis of CD was 24 years; this finding is similar to that of previous studies from other countries, which report the median age at diagnosis of CD to be approximately the mid-twenties. ${ }^{14,19-21}$ The male-to-female ratios in previous Korean epidemiological studies ranged from 2.2:1 to 2.8:1, similar to that in this study. ${ }^{13,22-25}$

As the etio-pathogenesis of $\mathrm{CD}$ remains unclear, the reason for the increased incidence remains unclear. However yet unknown environmental factors may be involved in the development of the disease and improvements in diagnostic procedures and practices may be contributing to the increased detection of the disease.

Table 2. Univariate and Multivariate Analysis for Factors Associated With Intestinal Resection

\begin{tabular}{|c|c|c|c|}
\hline \multirow{2}{*}{ Variable } & \multirow{2}{*}{$\begin{array}{c}\text { Univariate } \\
P \text {-value }\end{array}$} & \multicolumn{2}{|c|}{ Multivariate } \\
\hline & & OR $(95 \% \mathrm{Cl})$ & $P$-value \\
\hline \multicolumn{4}{|l|}{ Sex } \\
\hline \multicolumn{4}{|l|}{ Male $^{a}$} \\
\hline Female & 0.075 & $0.92(0.53-1.59)$ & 0.780 \\
\hline \multicolumn{4}{|c|}{ Age at diagnosis ${ }^{b}$} \\
\hline \multicolumn{4}{|l|}{$\mathrm{A} 1^{\mathrm{a}}$} \\
\hline$A 2$ & 0.041 & $1.59(0.74-3.42)$ & 0.220 \\
\hline A3 & 0.052 & $1.64(0.63-4.30)$ & 0.300 \\
\hline \multicolumn{4}{|l|}{ Location $^{b}$} \\
\hline \multicolumn{4}{|l|}{$\mathrm{L}^{\mathrm{a}}$} \\
\hline L2 & 0.280 & $0.79(0.42-1.49)$ & 0.470 \\
\hline L3 & 0.030 & $0.86(0.51-1.47)$ & 0.590 \\
\hline \multicolumn{4}{|l|}{ Behavior $^{b}$} \\
\hline \multicolumn{4}{|l|}{$\mathrm{B} 1^{\mathrm{a}}$} \\
\hline B2 & $<0.001$ & $12.00(6.80-21.17)$ & $<0.001$ \\
\hline B3 & $<0.001$ & 14.53 (7.56-27.92) & $<0.001$ \\
\hline Perianal fistula & 0.008 & $0.24(0.11-0.47)$ & $<0.001$ \\
\hline
\end{tabular}

${ }^{a}$ Reference categories for OR estimation.

${ }^{b} \mathrm{Age}$, disease location, and disease behavior in CD based on the Montreal classification.

$A 1,<17 ; A 2,17 \leq$ age $\leq 40 ; A 3$, $>40$; L1, ileal; $L 2$, colonic; $L 3$, ileocolonic; $B 1$, non-stricturing, non-penetrating; B2, stricturing; B3, penetrating. 
The distinction between CD and ITB is a diagnostic challenge as both diseases present with similar clinical, radiological, endoscopic, and histological features. ${ }^{26}$ In these cases, a more precise diagnosis is vital to avoid inadequate anti-TB therapy in patients with CD and potentially unsafe immunosuppressive treatment in patients with ITB. We expect that the therapeutic trial rate of anti-TB medication in patients with $\mathrm{CD}$ will decrease further as the incidence of ITB gradually decreases and the incidence and awareness of CD increases in Korea. In this study, 7.3\% of patients with $\mathrm{CD}$ were prescribed a therapeutic trial of anti-TB medication before they were ultimately diagnosed with $\mathrm{CD}$. This figure was lower than the $36 \%-47 \%$ reported in previous Korean studies. ${ }^{7,13,27}$ Advanced diagnostic techniques such as capsule endoscopy, small bowel enteroscopy, and immunological assays for Mycobacterium tuberculosis have played an important role in differentiating ITB and $\mathrm{CD}^{28}$

The proportion of patients presenting with ileo-colonic disease was similar to findings in previous Korean studies, where the number of L3 was about two-thirds of CD patients. ${ }^{13,15,23}$ The proportion of isolated colonic disease $(23.3 \%)$ in our study population was higher than that in previous Korean studies $(8.3 \%, 12.4 \%$, and $14.4 \%) .^{15,23,24}$ In our study, small bowel involvement of patients presenting with isolated colonic disease was mainly performed by using CT. The patients who had no small bowel involvement in CT were considered as isolated colonic disease without other specific studies. Patients with mild small bowel inflammation that was not detected on CT might have been classified as L2. The exact proportion of patients with L2 could be lower than what is shown in the results of this study. In a few epidemiological studies, isolated upper gastrointestinal disease has been mentioned, but the number of patients was very low, as in this study. ${ }^{17,29}$ In addition, patients presenting with upper gastrointestinal disease that coexisted with more distal disease in our study were fewer than those reported in other studies (12\%, 17.8\%, and 23.4\%). ${ }^{24,30,31}$ Because esophagogastroduodenoscopy and wireless capsule endoscopy for investigations of upper gastrointestinal involvement were not performed on all patients, this proportion could not be clearly defined and more complete evaluation of upper gastrointestinal (GI) disease would be required for more precise future analysis.

Ninety-six of 424 patients (22.6\%) presenting with inflammatory disease behavior had disease behavior changes, such that $47 \%$ of overall patients presented with stricturing or penetrating disease at their final evaluation in this study. In a Norwegian population-based 10-year follow-up study, the overall percentage of patients with stricturing or penetrating disease behavior was $36 \%$ at diagnosis, and $53 \%$ at 10 years. ${ }^{29}$ Fifty-four of 191 patients (28.3\%) initially showing B1-type behavior demonstrated other types at the last evaluation; $50.7 \%$ of patients presented with stricturing or penetrating disease behavior in another Korean study. ${ }^{15}$ Early detection and advanced medical treatment could contribute to the reduction in aggravation of disease behavior.

The proportion of patients who underwent intestinal resection during the follow-up period was lower than that previously reported in western countries and in Korea. In western population-based studies, the 10-year cumulative probability of bowel resection was $65 \%$ in Copenhagen, ${ }^{32}$ and $37.9 \%$ in Norway. ${ }^{29}$ In a recent study conducted in Denmark, the decrease in surgical intervention was paralleled by an increase in the administration of AZA and anti-TNF$\alpha$ blockers. ${ }^{33}$ A 5-year cumulative probability of a first major surgery decreased from $44.7 \%$ in a cohort diagnosed with CD during 1979-1986 to $19.6 \%$ in a cohort diagnosed from 2003 to $2011 .^{33}$ In previous Korean studies, the 10-year cumulative probability of bowel resection was $32.8 \%$, 43.5\%. ${ }^{15,27}$ In contrast to a previous Danish study, a recent study reported that the early use of infliximab did not reduce CDrelated surgery requirements in Korean patients with $\mathrm{CD}^{34}$ Risk factors for intestinal resection including ileal location, stricturing, or penetrating disease behavior, and younger age have been identified in several studies. ${ }^{24,35-39}$ In our study population, a significant correlation between complicated disease behavior and bowel surgery was present but other variables were not statistically significant.

One weakness of the present study is that this was a retrospective, observational study based on the medical records of patients who were diagnosed with CD in multiple centers, data regarding of smoking, interval from symptom to diagnosis, and family history were not extensively collected for all patients. Hospital-based studies compared to populationbased cohort studies may overestimate disease characteristics in patients. There is also a possibility of referral bias and better clinical outcomes, because patients who have intractable disease may undergo treatment at specialized clinics in Seoul.

In conclusion, a continued increase in the number of patients diagnosed with CD was found in Busan and Gyeongnam, as reported in other regions in Korea. We report results similar to those of other Korean studies in terms of sex distribution, age, and location of disease. The probability of the need for surgery was lower and complicated disease behavior developed in fewer cases than expected. A signifi- 
cant correlation between complicated disease behavior and bowel surgery was present. Future analyses of these patients will be required to determine the course of the disease in this population.

\section{REFERENCES}

1. Loftus EV, Jr. Clinical epidemiology of inflammatory bowel disease: Incidence, prevalence, and environmental influences. Gastroenterology 2004;126:1504-1517.

2. Bernstein CN, Shanahan F. Disorders of a modern lifestyle: reconciling the epidemiology of inflammatory bowel diseases. Gut 2008;57:1185-1191.

3. Lakatos PL. Recent trends in the epidemiology of inflammatory bowel diseases: up or down? World J Gastroenterol 2006;12:6102-6108.

4. Molodecky NA, Soon IS, Rabi DM, et al. Increasing incidence and prevalence of the inflammatory bowel diseases with time, based on systematic review. Gastroenterology 2012;142:46-54.

5. Kappelman MD, Rifas-Shiman SL, Kleinman K, et al. The prevalence and geographic distribution of Crohn's disease and ulcerative colitis in the United States. Clin Gastroenterol Hepatol 2007;5:1424-1429.

6. Bernstein CN, Wajda A, Svenson LW, et al. The epidemiology of inflammatory bowel disease in Canada: a population-based study. Am J Gastroenterol 2006;101:1559-1568.

7. Kappelman MD, Moore KR, Allen JK, Cook SF. Recent trends in the prevalence of Crohn's disease and ulcerative colitis in a commercially insured US population. Dig Dis Sci 2013;58:519525.

8. Goh K, Xiao SD. Inflammatory bowel disease: a survey of the epidemiology in Asia. J Dig Dis 2009;10:1-6.

9. Yang SK, Loftus EV, Jr., Sandborn WJ. Epidemiology of inflammatory bowel disease in Asia. Inflamm Bowel Dis 2001;7:260270.

10. Kim CG, Kim JW, Kim HD, et al. Clinical features of Crohn's disease in Korea. Korean J Gastroenterol 2002;40:173-180.

11. Ryu MK, Kim YH, Hyun JG, et al. Clinical investigations of Crohn's disease in Korea. Korean J Med 2001;60:46-50.

12. Park WK, Kim HS, Park JB, et al. Current trend of inflammatory bowel disease. J Korean Soc Coloproctol 2002;18:152-155.

13. Yang SK, Song IS, Kim YH, et al. Epidemiology of inflammatory bowel disease in the Songpa-Kangdong district, Seoul, Korea, 1986-2001: A KASID study. Gastroenterology 2003;124:A210.

14. Thia KT, Loftus EV, Jr., Sandborn WJ, Yang SK. An update on the epidemiology of inflammatory bowel disease in Asia. Am J Gastroenterol 2008;103:3167-3182.
15. Ye BD, Yang SK, Cho YK, et al. Clinical features and long-term prognosis of Crohn's disease in Korea. Scand J Gastroenterol 2010;45:1178-1185.

16. Loftus EV, Jr., Silverstein MD, Sandborn WJ, Tremaine WJ, Harmsen WS, Zinsmeister AR. Crohn's disease in Olmsted County, Minnesota, 1940-1993: incidence, prevalence, and survival. Gastroenterology 1998;114:1161-1168.

17. Silverberg MS, Satsangi J, Ahmad T, et al. Toward an integrated clinical, molecular and serological classification of inflammatory bowel disease: report of a Working Party of the 2005 Montreal World Congress of Gastroenterology. Can J Gastroenterol 2005;19(Suppl A):5A-36A

18. Satsangi J, Silverberg MS, Vermeire S, Colombel JF. The Montreal classification of inflammatory bowel disease: controversies, consensus, and implications. Gut 2006;55:749-753.

19. Munkholm P. Crohn's disease-occurrence, course and prognosis. An epidemiologic cohort-study. Dan Med Bull 1997;44:287302.

20. Ekbom A, Helmick C, Zack M, Adami HO. The epidemiology of inflammatory bowel disease: a large, population-based study in Sweden. Gastroenterology 1991;100:350-358.

21. Gollop JH, Phillips SF, Melton LJ, 3rd, Zinsmeister AR. Epidemiologic aspects of Crohn's disease: a population based study in Olmsted County, Minnesota, 1943-1982. Gut 1988;29:49-56.

22. Park SH, Yang SK, Park SK, et al. Long-term prognosis of Crohn's disease and its temporal change between 1981 and 2012: a hospital-based cohort study from Korea. Inflamm Bowel Dis 2014;20:488-494.

23. Yang SK, Yun S, Kim JH, et al. Epidemiology of inflammatory bowel disease in the Songpa-Kangdong district, Seoul, Korea, 1986-2005: a KASID study. Inflamm Bowel Dis 2008;14:542 549.

24. Moon CM, Park DI, Kim ER, et al. Clinical features and predictors of clinical outcomes in Korean patients with Crohn's disease: a Korean Association for the Study of Intestinal Diseases multicenter study. J Gastroenterol Hepatol 2014;29:74-82.

25. Choi JH, Kim ES, Cho KB, et al. Old age at diagnosis is associated with favorable outcomes in korean patients with inflammatory bowel disease. Intest Res 2015;13:60-67.

26. Kim BJ, Choi YS, Jang BI, et al. Prospective evaluation of the clinical utility of interferon- $\gamma$ assay in the differential diagnosis of intestinal tuberculosis and Crohn's disease. Inflamm Bowel Dis 2011;17:1308-1313.

27. Sjöberg D, Holmström T, Larsson M, et al. Incidence and clinical course of Crohn's disease during the first year - results from the IBD Cohort of the Uppsala Region (ICURE) of Sweden 2005-2009. J Crohns Colitis 2014;8:215-222. 
28. Pulimood AB, Amarapurkar DN, Ghoshal U, et al. Differentiation of Crohn's disease from intestinal tuberculosis in India in 2010. World J Gastroenterol 2011;17:433-443.

29. Solberg IC, Vatn MH, Høie O, et al. Clinical course in Crohn's disease: results of a Norwegian population-based ten-year follow-up study. Clin Gastroenterol Hepatol 2007;5:1430-1438.

30. Kim B, Park SD, Choi SI, Lee SH, Lee KY. The Characteristics of Crohn's Disease in Korea According to the Montreal Classification. J Korean Soc Coloproctol 2009;25:300-305.

31. Park JB, Yang SK, Myung SJ, et al. Clinical characteristics at diagnosis and course of Korean patients with Crohn's disease. Korean J Gastroenterol 2004;43:8-17.

32. Jess T, Riis L, Vind I, et al. Changes in clinical characteristics, course, and prognosis of inflammatory bowel disease during the last 5 decades: a population-based study from Copenhagen, Denmark. Inflamm Bowel Dis 2007;13:481-489.

33. Rungoe C, Langholz E, Andersson M, et al. Changes in medical treatment and surgery rates in inflammatory bowel disease: a nationwide cohort study 1979-2011. Gut 2014;63:1607-1616.
34. Kim NH, Jung YS, Moon CM, et al. Long-term clinical outcomes of korean patient with Crohn's disease following early use of infliximab. Intest Res 2014;12:281-286.

35. Lakatos PL, Szalay F, Tulassay Z, et al. Clinical presentation of Crohn's disease. association between familial disease, smoking, disease phenotype, extraintestinal manifestations and need for surgery. Hepatogastroenterology 2005;52:817-822.

36. Nemetz A, Molnar T, Zagoni T, et al. Phenotypes defined by the "Vienna Classification" in 100 Hungarian patients with Crohn's disease. Rev Esp Enferm Dig 2003;95:533-538.

37. Oostenbrug LE, van Dullemen HM, te Meerman GJ, Jansen PL, Kleibeuker JH. Clinical outcome of Crohn's disease according to the Vienna classification: disease location is a useful predictor of disease course. Eur J Gastroenterol Hepatol 2006;18:255261.

38. Wolters FL, Russel MG, Sijbrandij J, et al. Phenotype at diagnosis predicts recurrence rates in Crohn's disease. Gut 2006;55:11241130.

39. Gurudu S, Fiocchi C, Katz JA. Inflammatory bowel disease. Best Pract Res Clin Gastroenterol 2002;16:77-90. 